Thorax (1969), 24, 667.

\title{
Cor triatriatum with pericardial agenesis
}

\author{
M. J I MÉNEZ MARTÍNEZ ${ }^{1}$, J.S. FRANCO VÁZQUEZ, \\ R. GUTÍ́R REZ BOSQUE, J. J. PÉREZ ALVAREZ, AND \\ R. ARGUUERO SÁNCHEZ \\ From the Departments of Cardiovascular Surgery and Cardiology, Hospital de Pediatria, \\ Centro Médico Nacional, México City, México
}

A case of cor triatriatum associated with pericardial agenesis, which was successfully treated, is reported. Details of the clinical picture and surgical treatment are given, with emphasis on the good prognosis which results when the diagnosis is made before attempting surgical correction.

Cor triatriatum is a rather uncommon congenital malformation; it was first described by Church in 1868 . Since then 72 cases have been reported in the literature, of which only 22 have been correctly diagnosed pre-operatively or at operation (Ahn, Hosier, and Sirak, 1968; Enjalbert, Calazel, Bounhoure, Vadhat, Puel, and Meriel, 1966; Lasalle, Ethier, Stanley, and Davignon, 1963; McGuire, Nolan, Reeve, and Dammann, 1965 ; Neufeld, Pauzner, Gueron, Deutsch, and Cohen, 1965 ; Soulié, Vernant, Corone, Galey, Bouchard, Poisson, and Guérin, 1965).

The association of cor triatriatum with pericardial agenesis has not been reported previously. In the present case the diagnosis of cor triatriatum was made before attempting surgical repair.

\section{CASE REPORT}

R. H. J., a 10-year-old boy, was first seen in September 1965 because of coughing episodes. A heart murmur had been heard six months previously and there was a history of repeated upper respiratory infections, exertional dyspnoea, and fatigue.

On physical examination the child was poorly developed, with no evidence of congestive heart failure. The chest was deformed with a prominent precordium. The maximum cardiac impulse was visible and palpable at the sixth left intercostal space over the anterior axillary line. A thrill was felt at the apex and along the sternal border. A grade 2 to $3 / 4$ systolic murmur was heard at the apex. The second heart sound was split and the pulmonary component accentuated. Peripheral pulses were found to be normal with a blood pressure of $120 / 60 \mathrm{~mm}$. Hg.

Routine laboratory tests were within normal limits.

A chest radiograph showed cardiac enlargement and the heart shadow was displaced to the left, the pul-

1Present address: Av. la Purisima No. 3227, Col. Chapalita, Guadalajara, Jal., Mexico. monary artery was prominent, and the bronchovascular markings were increased (Fig. 1).

The electrocardiogram was consistent with right ventricular hypertrophy and enlargement of the left and right atria (Fig. 2).

Cardiac catheterization showed (Table) hypertension of the right ventricle and pulmonary artery. The pulmonary artery wedge pressure was $23 \mathrm{~mm}$. Hg. No shunts were demonstrated. Trans-septal catheterization was unsuccessful.

A selective pulmonary artery angiocardiogram demonstrated a dilated pulmonary artery and veins and delayed filling of the left atrium with a small left ventricle (Fig. 3).

The patient was operated upon with a diagnosis of cor triatriatum on 6 November 1965 through a midline sternotomy. The pericardium was absent and the heart was displaced to the left costophrenic angle (Fig. 4). The superior and inferior venae cavae were cannulated as was the ascending aorta by means of an Allen-Jiménez cannula (Jiménez Martínez, Pérez Alvarez, and Argüero Sánchez, 1968).

Total body perfusion was started by means of a disc oxygenator. The right atrium was opened, an intact auricular septum was identified, and three puncture holes of the attempted trans-septal catheterization were seen. An incision was made on the upper portion of the septum opening the accessory chamber. A white greyish membrane with a $6-\mathrm{mm}$. orifice dividing both left atrial chambers was found; this membranous diaphragm was completely excised (Fig. 5). The mitral valve was normal. The interatrial septum and right atrium were closed. Total perfusion lasted 27 minutes and the blood pressure returned to normal after the procedure.

The post-operative course was uneventful and the patient was discharged from hospital on the 14th post-operative day. The patient has been controlled in the out-patient clinic during the last three years and is asymptomatic. Physical development is now normal. There are no murmurs and the second sound remains split. 


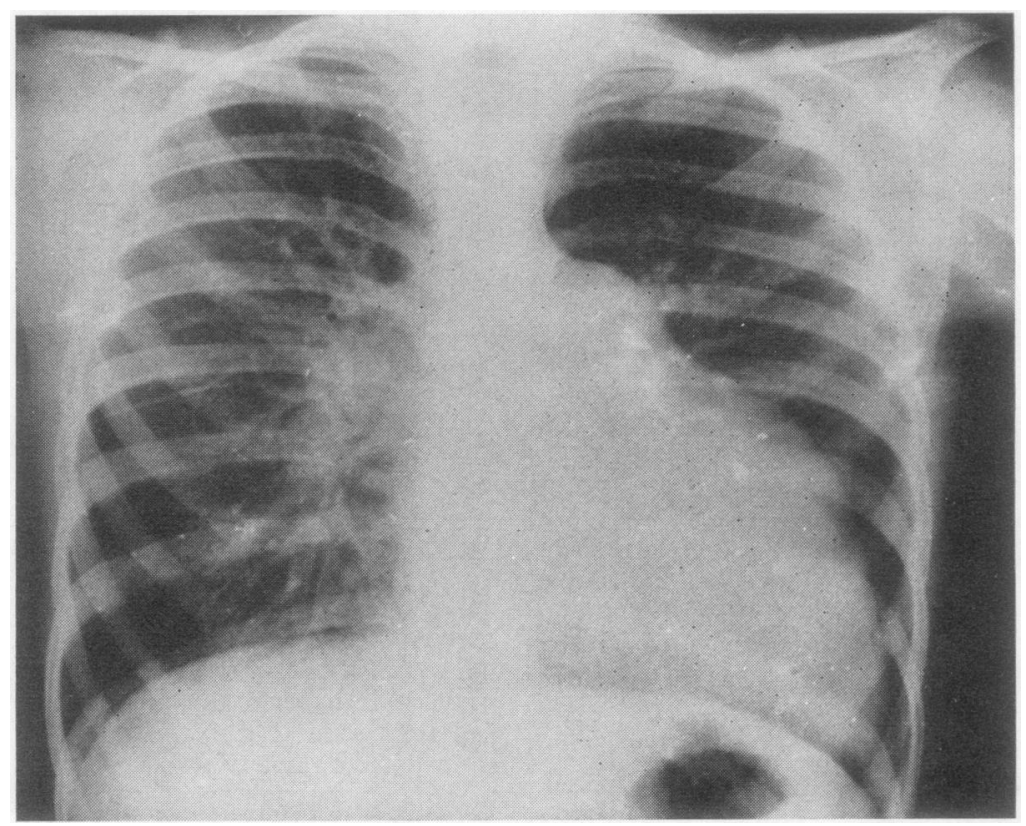

FIG. 1. Postero-anterior chest radiograph showing cardiomegaly with the heart shadow shifted toward the left. There is a flattened left heart border and a well-defined pulmonary artery segment.

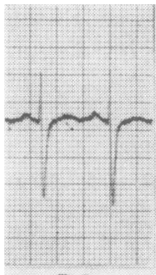

DI

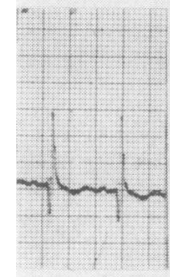

V4D

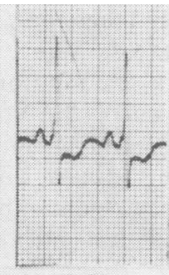

DII

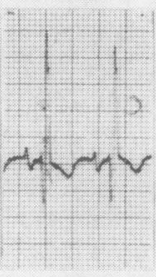

VI

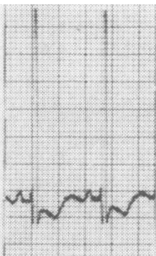

D III

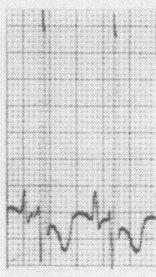

V 2

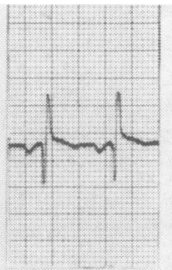

GYR

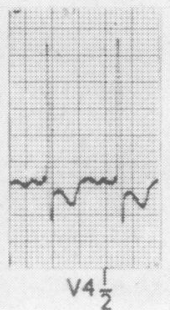

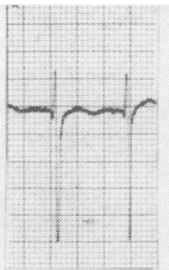

aVL

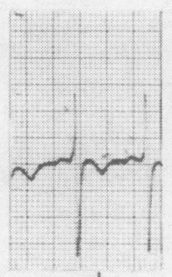

V $5 \frac{1}{2}$

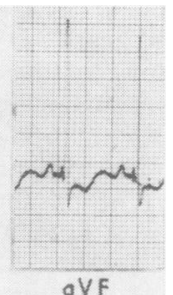

aVF

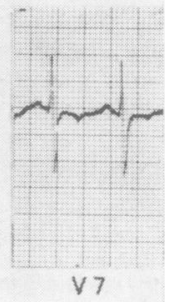

FIG. 2. Electrocardiogram. 
FIG. 3. Angiocardiogram, posteroanterior and lateral views, shows the third chamber filled and an empty space in between this and the left ventricle.
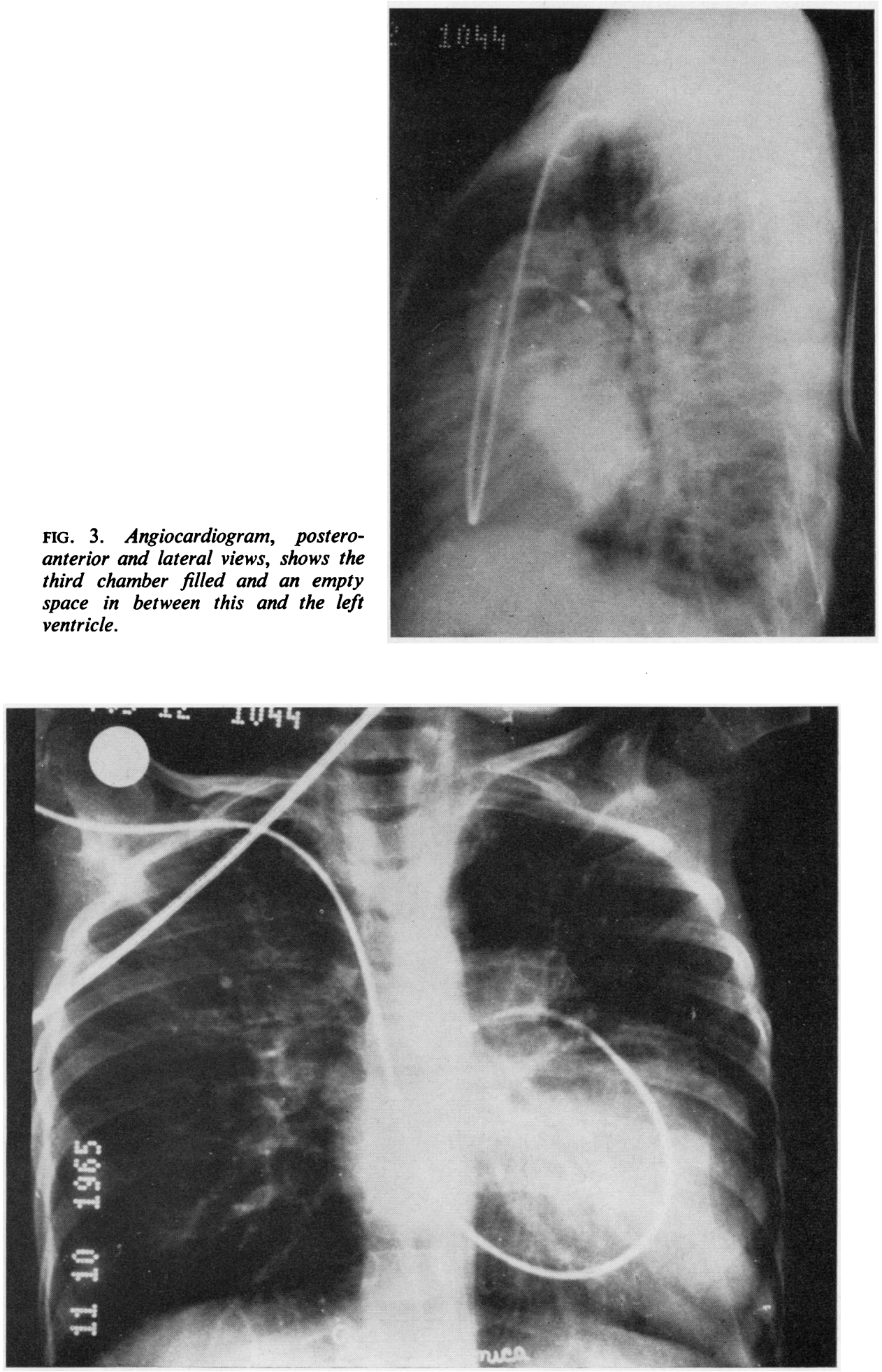


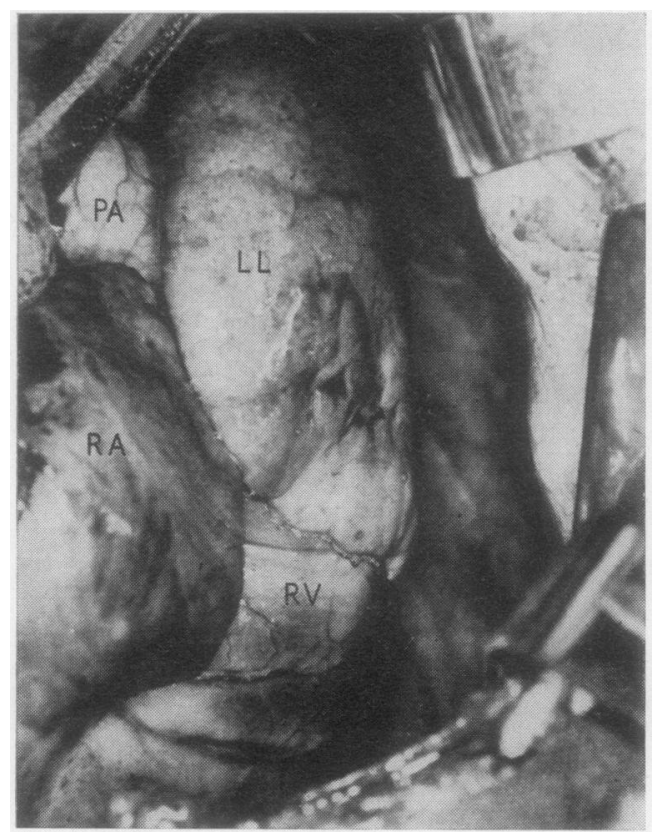

FIG. 4. Photograph taken during operation shows the heart displaced to the left and absence of the pericardium. Pulmonary artery $(P A)$, right atrium $(R A)$, right ventricle $(R V)$, and left lung $(L L)$.

FIG. 5. Shows the excision of the diaphragm (D) with a 6-mm. hole communicating the accessory atrial chamber $(A A C h)$ with the true left atrium $(L A)$.

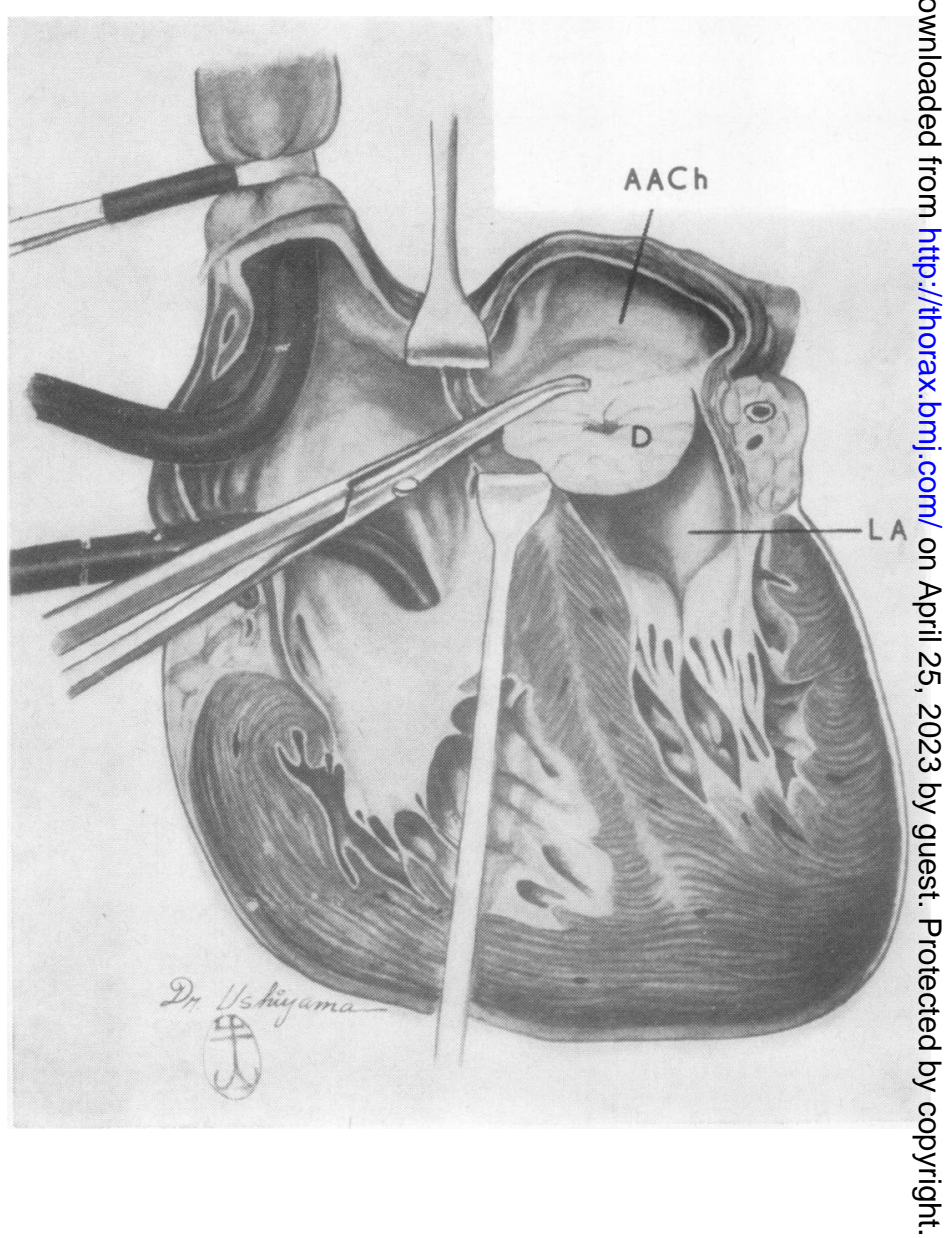


T A B L E

CATHETERIZATION DATA

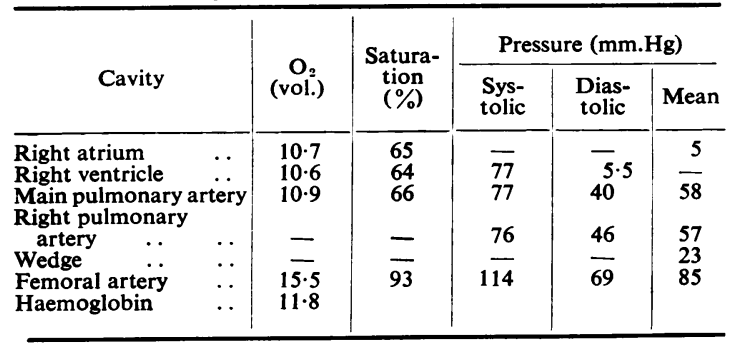

\section{COMMENTS}

Cor triatriatum is a congenital anomaly of the heart in which all the pulmonary veins drain into an accessory chamber which is incompletely communicated, due to failure of the common pulmonary vein to become incorporated with the left atrium in a normal manner (Edwards, DuShane, Alcott, and Burchell, 1951). In the present case it was also associated with pericardial agenesis resulting from incomplete development of the pleuropericardial folds (Ellis, Leeds, and Himmelstein, 1959).

Since this was first described by Church (1868), several authors (Ahn et al., 1968 ; Lacquet, Los, Nauta, and Brom, 1966 ; Niwayama, 1960 ; Neufeld et al., 1965) have reviewed the literature. The first successful operation was performed by Vineberg and Gialloretto in 1956 ; since then, 22 patients have been diagnosed at operation or preoperatively (Ahn et al., 1968 ; Enjalbert et al., 1966 ; Lasalle et al., 1963 ; McGuire et al., 1965 ; Neufeld et al., 1965 ; Soulié et al., 1965).

Of this group of patients, only three (Lasalle et al., 1963 ; McGuire et al., 1965 ; Miller, Ongley, Anderson, Kincaid, and Swan, 1964) died in the immediate post-operative period. Seven additional patients, operated upon with an incorrect diagnosis, died during or following surgery (Abedrop, Espino Vela, and Correa, 1961 ; Beller, Childers, Eckner, Duchelle, Ranniger, and Rabinowitz, 1967 ; McGuire et al., 1965). Thus a correct diagnosis is an indispensable step in the correction of this anomaly.

The clinical picture is that of mitral stenosis with variable clinical manifestations, depending on the degree of stenosis of the communication with the true left atrium.

Usually, dyspnoea on exertion, failure to thrive, and cyanosis are present, as in our patient, and the more common physical findings are apical murmurs, right ventricular hypertrophy, and accentua- tion of the pulmonary closure sound. These findings are also described in other anomalies such as congenital mitral stenosis and stenosis of the pulmonary veins. Several types of heart murmur have been reported; but a systolic murmur at the left sternal border and at the apex has been described most often.

Chest radiographs may show varying degrees of cardiac enlargement, a prominent pulmonary artery, and evidence of pulmonary venous hypertension.

In our patient the typical picture of pericardial agenesis was added (Dimich, Grossman, Bowman, and Griffiths, 1965 ; Ellis et al., 1959 ; Tubbs and Yacoub, 1968). The electrocardiographic findings usually show severe right ventricular hypertrophy. The catheterization studies showed an elevated right ventricle, pulmonary artery, and wedge pressures. During catheterization an elevated pressure in the pulmonary veins and accessory chamber is highly suggestive of cor triatriatum. A selective angiocardiogram of the pulmonary artery is probably the best way to demonstrate the lesion. It usually shows a dilated pulmonary artery and veins and delayed emptying of the accessory chamber.

Cor triatriatum is easily corrected surgically with the aid of extracorporeal circulation.

We are greatly indebted to Dr. E. Hushiyama for the drawing in Fig. 5, and to Dr. Mario Villamichel for his assistance.

\section{REFERENCES}

Abedrop, E., Espino Vela. J., and Correa, R. (1961). Estudio de un caso de corazón triauricular (Cor triatriatum). Arch. Inst. Cardiol. Méx., 31, 482.

Ahn, C., Hosier, D. M., and Sirak, H. D. (1968). Cor triatriatum. A case report and review of other operative cases. J. thorac. cardiovasc. Surg., 56, 177.

Beller, B., Childers, R., Eckner, F., Duchelle, R., Ranniger, K., and Rabinowitz, M. (1967). Cor triatriatum in the adult complicated by mitral insufficiency and aortic dissection. Amer. J. Cardiol.,
19,749 .

Church, W. S. (1868). Congenital malformation of heart; abnormal septum in left auricle. Trans. path. Soc. Lond., 19, 188.

Dimich, I., Grossman, H., Bowman, F. O., and Griffiths, S. P. (1965). Congenital absence of the left pericardium. Amer. J. Dis. Child., $110,309$.

Edwards, J. E., DuShane, J. W., Alcott, D. L., and Burchell, H. B. (1951). Thoracic venous anomalies. III. Atresia of the common pulmonary vein, the pulmonary veins draining wholly into the superior vena cava (Case 3). IV. Stenosis of the common pulmonary vein (Cor triatriatum) (Case 4). Arch. Path., 51, 446.

Ellis, K., Leeds, N. E., and Himmelstein, A. (1959). Congenital deficiencies in the parietal pericardium. Amer. J. Roentgenol., 82, 125.

Enjalbert, A., Calazel, P., Bounhoure, J. P., Vadhat, F., Puel, P. and Meriel, P. (1966). Coeur triatrial chez une adulte. Cure chirurgicale sous circulation extra-corporelle. Arch. Mal. Caur, 59, 1893.

Jiménez Martínez, M., Pérez Alvarez, J. J., and Argüero Sánchez, R. (1968). Empleo de la cánula aortica Allen-Jiménez para perfusión arterial en 180 casos de circulación extracorpórea. Arch. Inst. Cardiol. Méx., 38, 573 . 
Lacquet, L. K., Los, J. A., Nauta, J., and Brom, A. G. (1966). Cor triatriatum. Thorax, 21, 175.

Lasalle, R., Ethier, M., Stanley, P., and Davignon, A. (1963). Cor triatriatum: report of a case with emphasis on cineangiocardiography. Canad. med. Ass. J., 89, 616.

McGuire, L. B., Nolan, T. B., Reeve, R., and Dammann, J. F. (1965). Cor triatriatum as a problem of adult heart disease. Circulation, 31, 263.

Miller, G. A. H., Ongley, P. A., Anderson, M. W., Kincaid, O. W., and Swan, H. J. (1964). Cor triatriatum: hemodynamic and angiocardiographic diagnosis. Amer. Heart J., 68, 298.
Neufeld, H. N., Pauzner, Y., Gueron, M., Deutsch, V., and Cohen, B. (1965). Cor triatriatum: report of a case successfully operaced with special reference to angiocardiographic diagnosis. Israe med. Sci., 1, 71 .

Niwayama, G. (1960). Cor triatriatum. Amer. Heart J., 59, 291.

Soulié, P., Vernant, P., Corone, P., Galey, J. J., Bouchard, F., Poissgg, M., and Guérin, F. (1965). Le coeur triatrial. Arch. Mal. Ceerar, $58,1825$.

Tubbs, O. S., and Yacoub, M. H. (1968). Congenital pericardFal defects. Thorax, 23, 598 .

Vineberg, A., and Gialloreto, O. (1956). Report of a successE్bl operation for stenosis of common pulmonary vein (cor triatras tum). Canad. med. Ass. J., 74, 719. 